\title{
Determinants of life-history traits in a fish ectoparasite: a hierarchical analysis
}

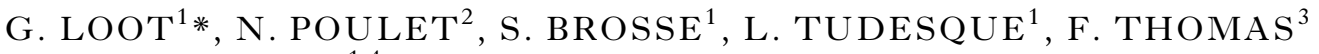 \\ and $\mathrm{S}$. BLANCHET ${ }^{1,4}$ \\ ${ }^{1}$ Laboratoire Evolution et Diversité Biologique, U.M.R 5174, C.N.R.S-Université Paul Sabatier, 118 route de Narbonne, \\ F-31062 Toulouse cedex 4, France \\ ${ }^{2}$ ONEMA, Le Nadar Hall C 5 sq Félix Nadar 94300 Vincennes, France \\ ${ }^{3}$ IRD, MIVEGEC (UMR CNRS/IRD/UM1), 911 Av. Agropolis, BP 64501, FR-34394 Montpellier cedex 5, France \\ ${ }^{4}$ Station Expérimentale du CNRS à Moulis, U.S.R 2936, 09100 Moulis, France
}

(Received 22 October 2010; revised 9 December 2010 and 12 Fanuary 2011; accepted 12 Fanuary 2011)

\section{S U MMARY}

Objective. Unravelling the determinants of parasite life-history traits in natural settings is complex. Here, we deciphered the relationships between biotic, abiotic factors and the variation in 4 life-history traits (body size, egg presence, egg number and egg size) in the fish ectoparasite Tracheliastes polycolpus. We then determined the factors affecting the strength of the trade-off between egg number and egg size. Methods. To do so, we used 4-level (parasite, microhabitat, host and environment) hierarchical models coupled to a field database. Results. Variation in life-history traits was mostly due to individual characteristics measured at the parasite level. At the microhabitat level (fins of fish hosts), parasite number was positively related to body size, egg presence and egg number. Higher parasite number on fins was positively associated with individual parasite fitness. At the host level, host body size was positively related to the individual fitness of the parasite; parasites were bigger and more fecund on bigger hosts. In contrast, factors measured at the environmental level had a weak influence on life-history traits. Finally, a site-dependent trade-off between egg number and egg size existed in this population. Conclusion. Our study illustrates the importance of considering parasite life-history traits in a hierarchical framework to decipher complex links between biotic, abiotic factors and parasite life-history traits.

Key words: freshwater ecosystem, hierarchical model, trade-off, fecundity, multilevel models, egg, Copepods, Cyprinidae, parasite.

\section{INTRODUCTION}

In a rapidly changing world, understanding the factors controlling the spatial distribution of parasites is of great importance for biodiversity conservation (Wimberly et al. 2008). For this purpose, it is necessary to acquire precise knowledge of the biological mechanisms underlying the dynamics of parasite populations (Lafferty, 2009a). Parasite lifehistory traits such as fecundity, body size and growth are perfect candidates for such a purpose since they determine the survival, propagule pressure and transmission rate of parasites (Poulin, 1995a).

The probability of a free-living parasite encountering and infecting an appropriate host is likely to be low and stochastic (Combes, 2001; Hakalahti et al. 2004). Hence, for most parasite species, increased fecundity is likely to be a selected strategy for improving host encounter rate (Poulin, 1995b). An increased fecundity is likely to improve host encounter by producing larger propagules with a higher

* Corresponding author: Laboratoire Evolution et Diversité Biologique, U.M.R 5174, C.N.R.S - Université Paul Sabatier, 118 route de Narbonne, F-31062 Toulouse cedex 4, France. Tel: +33561558581. Fax: +33561556728. E-mail: loot@cict.fr rate of survival (Hakalahti et al. 2004; Herreras et al. 2007). Because the number and size of propagules compete directly for a limited energy budget, a phenotypic trade-off is expected between them (Smith and Fretwell, 1974; Roff, 1992; Stearns, 1992). Even if rarely demonstrated in parasitic organisms (but see Rossin et al. 2005; Timi et al. 2005; Herreras et al. 2007), it is assumed that withinpopulation variability in female body size determines the strength and the shape of the trade-off between propagule size and number (Roff, 1992). In natural populations of free-living organisms, environmental conditions can also influence this trade-off (Blanckenhorn and Heyland, 2004; Jessup and Bohannan, 2008). For instance, Schluter et al. (1991) showed that beneficial environments, and specifically the positive effects of nutrition on fitness traits, might mask trade-offs expected under some selective regimes. Analysis of the trade-off between egg number and egg size therefore requires knowledge of environmental conditions in which organisms are living, and also on the relationships between those conditions and other life-history traits (Jessup and Bohannan, 2008). In parasites, these relationships remain largely unexplored, mainly because of the difficulty in collecting information. 
Table 1. Distance from the source, mean temperature, number of hosts and parasite samples for each sampling site

\begin{tabular}{|c|c|c|c|c|}
\hline Sampling site & $\begin{array}{l}\text { Distance from } \\
\text { the source }(\mathrm{km})\end{array}$ & $\begin{array}{l}\text { Mean temperature } \\
(\mathrm{CV})\end{array}$ & $\begin{array}{l}\text { Number of hosts } \\
\text { (mean body size } \mathrm{mm} \text { ) }\end{array}$ & $\begin{array}{l}\text { Total number of parasites } \\
\text { (mean body size } \mathrm{mm} \text { ) }\end{array}$ \\
\hline Bannes & 47 & $15 \cdot 28(0 \cdot 046)$ & $10(197 \cdot 70)$ & $111(2 \cdot 43)$ \\
\hline Capelle & 53 & $16 \cdot 11(0 \cdot 027)$ & $14(157 \cdot 21)$ & $71(2 \cdot 12)$ \\
\hline Fuel & 68 & $17 \cdot 57(0 \cdot 042)$ & $11(217 \cdot 63)$ & $116(2 \cdot 44)$ \\
\hline Serres & 71 & $17 \cdot 62(0 \cdot 043)$ & $10(232.90)$ & $147(2 \cdot 53)$ \\
\hline Albinet & 76 & $17 \cdot 70(0 \cdot 061)$ & $10(205 \cdot 50)$ & $211(2 \cdot 70)$ \\
\hline Navech & 95 & $18 \cdot 02(0 \cdot 046)$ & $12(166 \cdot 91)$ & $145(2 \cdot 48)$ \\
\hline Saint Just & 101 & $18.93(0.037)$ & $9(196 \cdot 88)$ & $160(2 \cdot 59)$ \\
\hline Pignac & 119 & $20 \cdot 79(0 \cdot 051)$ & $7(196 \cdot 73)$ & $41(2 \cdot 63)$ \\
\hline
\end{tabular}

An additional difficulty arises from the fact that parasites are constrained in a nested scheme in which components are highly inter-dependent (Keitt and Urban, 2005; McMahon and Diez, 2007). Specifically, parasites are nested within their hosts that are themselves nested within the surrounding environment (Morand, 1996; Seppala et al. 2008). Accordingly, life-history strategies adopted by parasites are likely to be under the combined pressure of many interacting forces such as host density, host condition or abiotic factors (Morand, 1996; Eisen and Schall, 2000; Hakalahti et al. 2004; Seppala et al. 2008). Modelling hierarchically structured data in natural settings has become increasingly efficient through the development of specific statistical models (Keitt and Urban, 2005; Diez and Pulliam, 2007; McMahon and Diez, 2007). These models should prove powerful for disentangling relationships between physical/biological factors and variation in life-history traits of parasites in natural settings (Byers et al. 2008).

Tracheliastes polycolpus von Nordman 1832 (Copepoda: Lernaeopodidae) is an ectoparasite of wild fish populations distributed throughout the northern Paleartic region. Tracheliastes polycolpus completes its holoxenous life cycle in cyprinid fishes. The common host in Western Europe is the dace Leuciscus leuciscus Linnaeus (Loot et al. 2004). Only sexually mature females are parasitic and they are anchored to host fins and feed on epithelial cells and mucus of the host, characteristically damaging fins (Loot et al. 2004). During their parasitic phase, females develop 2 egg sacs that each carry several hundred eggs. Eggs hatch throughout the year (Fryer, 1982) as free-living copepodids, which then develop into 4 successive chalimus stages. Within egg sacs, eggs are at the same stage of maturation indicating that all eggs hatch simultaneously. In females, the last stage is morphologically modified for attachment to the host (Kabata and Cousens, 1973). Adult males are free-swimming and dwarfed. They usually die very soon after mating, and never become parasitic (Kabata, 1986).

The goals of this study were 2 -fold. First, we aimed to evaluate how the variability observed in the wild for 4 life-history traits of $T$. polycolpus (body size, egg presence, egg number and egg size) segregates across multiple levels of measurement (site level, host level, fin level and parasite level). To assess the relative roles of abiotic and biotic variables in explaining lifehistory variation we sampled $T$. polycolpus individuals along a river gradient and used a hierarchical modelling framework which explicitly integrates possible associations across the above-cited levels (McMahon and Diez, 2007). Second, we studied the phenotypic trade-off between egg number and egg volume of $T$. polycolpus within and between these sampling sites. We analysed co-variation in clutch investment and allocation using female body size as a control in order to gain insight into the factors determining the presence or absence of this trade-off.

\section{MATERIALS AND METHODS}

\section{Sampling design}

A hierarchical design was used to capture a range of environmental conditions across an altitudinal gradient of approximately $70 \mathrm{~km}$ along the Viaur river continuum in southwestern France. Eight study sites were sampled along the river gradient, each site was between 1000 and $2000 \mathrm{~m}^{2}$ in size (see Table 1). Sampling was performed in early summer within the same week (16-20 June 2005). Each site was separated by at least a $3-18 \mathrm{~km}$ river stretch to cover all environmental characteristics met by L. leuciscus and T. polycolpus. We hereafter use the term 'site level' to refer to inference at the level of the study site. Between 7 and 14 Leuciscus leuciscus were sampled by electrofishing (Deka 6000 DC, Deka, Marsberg, Germany) within each site (see Table 1 for more details). The term 'host level' hereafter refers to inference at the level of the individual host. We use the term 'microhabitat level' to refer to inference at the level of the host fins and the term 'parasite level' to refer to inference at the level of the individual parasite.

\section{Parasite life-history trait measurements}

Overall, 1002 individual parasites were collected on 83 fish from 8 sampling sites (see Table 1 for more 
details). All parasites for a given host were sampled. Each parasite was measured for 4 life-history traits: body size, presence/absence of eggs, egg size, and number of eggs. Tracheliastes polycolpus were individually placed in $1.5 \mathrm{ml}$ Eppendorf $\AA$ tubes containing river water to keep them alive during transport to the laboratory. At the laboratory, a picture of each parasite was taken with a digital camera. The camera (Nikon Coolpix 4500®) was fixed on a binocular microscope, and a metric ruler was placed to provide a baseline scale. The same focal length was kept in order to avoid any picture distortion. We used the Image Tool software (free download at http://ddsdx. uthscsa.edu/dig/itdesc.html) to measure body size (measured as the trunk length) of all parasites. We noted whether females carried egg sacs. When egg sacs were present, the egg diameter (as a surrogate of the size of the egg) was measured for a random sample of 10 eggs per female. We identified 2 distinct developmental stages of eggs according to their colouration (4 black dots were visible on one stage but not on the other one) and size. The first egg stage was significantly smaller (mean \pm S.D.; $0 \cdot 159 \mathrm{~mm} \pm 0 \cdot 015$ ) than the second stage $(0 \cdot 169 \mathrm{~mm} \pm 0 \cdot 019)$ (ANOVA, D.F. $=1,447 ; \mathrm{F}=37 \cdot 91 ; P<0 \cdot 001)$. To avoid statistical biases in egg size analysis we only considered females with egg sacs containing eggs of the second stage (that we considered as mature eggs). After the picture, egg sacs were removed from each parasite and individually stored in Gilson's solution for 2 months to digest the sac tissues and separate eggs. Then, the number of eggs in $1 \mathrm{egg}$ sac was determined at $10 \times$ magnification.

\section{Biotic and abiotic measurements}

Site level. Abiotic variables considered at the site level were the mean annual water temperature $\left({ }^{\circ} \mathrm{C}\right)$, the mean water velocity $\left(\mathrm{cm} . \mathrm{s}^{-1}\right)$ and a measure of water quality. Tracheliastes polycolpus is anchored to the fins of its host, and it can directly be affected by flow rate (energy could be allocated for facing the current velocity rather than for developing gonads) and by the temperature of the surrounding environment (Boxshall, 2005). Mean annual water temperature at each site was extracted from a continuous data recorder (Tynitag $\left.{ }^{\circledR}\right)$. Temperature was recorded (to the nearest $0 \cdot 1{ }^{\circ} \mathrm{C}$ ) every $6 \mathrm{~h}$ during the year preceding the parasite sampling. During the sampling period, water velocity was recorded at 25 haphazardly selected points within each site using a wading rod and an electronic flow meter (to the nearest $\left.0.05 \mathrm{~m} . \mathrm{s}^{-1}\right)$. An average value was calculated and used to characterize flow rate in each site. We finally calculated the diatom index that is an integrative indicator of water quality and environmental conditions (water chemistry and water oxygenation) of a given site (Cox, 1991; Taylor et al. 2007). This index is based on the presence/absence of certain diatom species in samples, some species being indicators of good water quality, others not. Epilithic diatom assemblages were sampled at each site by brushing 5 cobbles located in riffle or running sections. Each sample was cleaned in boiling hydrogen peroxide and chloridric acid. After removing all traces of chloridric acid, the diatom frustules were dried onto coverslips and mounted onto glass slides in Naphrax ${ }^{\circledR}$ (Northern Biological Supplies, Ipswich, UK). At least 400 frustules per sample were identified to species level and counted under a photonic microscope at $\times 1000$ magnification (see Grenouillet et al. 2008 for more details). The diatom index was calculated with the OMNIDIA 4.2 software (Lecointe et al. 1993). The diatom index varies from 1 to 20, higher values indicating better water quality. The only biotic variable considered at the site level was the host density. The dynamics of parasite populations is known to be partly influenced by the density of hosts in a given habitat (Grenfell and Harwood, 1997; Arneberg et al. 1998). We therefore evaluated dace density in each site by electrofishing (see above) using the 2-pass depletion method classically used for evaluating fish density in streams (Bohlin et al. 1989). Within each site, we delimited a stream reach (from 300 to $780 \mathrm{~m}^{2}$ ) that was as representative as possible of the entire site, and we captured dace in this reach. Dace were stored in aerated tanks between the 2 passes. Dace density was estimated using the method of Carle and Strub (1978).

Host level. Studies have shown that parasite lifehistory traits can be affected by characteristics of the host such as its age, size, diet, or immune status (Tsai et al. 2001; Krasnov et al. 2002; Barber, 2005). Thus, after being captured, dace were anaesthetized (eugenol solution), measured (total body length, $\pm 1 \mathrm{~mm}$ ) and weighed ( $\pm 1 \mathrm{~g}$ ) before being released in their respective sites. The overall condition of each host was estimated using the Fulton's condition factor $\left(\mathrm{K}=\right.$ weight per length $\left.{ }^{3}\right)$ (Nash et al. 2006). Host body condition has been shown to increase the host immune function and thus the host ability to resist or tolerate parasites (Krist et al. 2004; Blanchet et al. 2009). Both the host body length (which is correlated to age in fish) and the condition factor were used as potential predictors of parasite life-history traits at the host level.

Microhabitat level. Two variables related to this level were considered to potentially influence lifehistory traits of $T$. polycolpus: the number of conspecifics present on each fin and the identity of the fin where the parasite was sampled (i.e. pelvic, pectoral, dorsal, anal or caudal fin). Changes in fecundity may be explained by the number of conspecifics sharing a host, which could influence the parasite's per capita average fecundity (Anderson, 1993). Intraspecific competition can be strong in parasites (Crompton, 
1991; Patrick, 1991; Hawlena et al. 2007), and we thus suppose that the number of conspecifics per fin could negatively influence the quantity of nutrients available for parasite growth. In addition, a recent study (Timi et al. 2010) demonstrated that the attachment site selected by a parasitic copepod (Neobrachiella spinicephala) on its fish host affected both parasite body mass and egg production. Patterns of microhabitat preferences have been highlighted in T. polycolpus, with individuals being anchored preferentially (particularly when at low density) on pectoral, anal and pelvic fins (Loot et al. 2004). According to Timi et al. (2010), we would predict higher fitness in individuals on those fins.

Parasite level. Variability in parasite female body size has been reported as a source of variation in reproductive investment for many parasites (e.g. Rossin et al. 2005; Herreras et al. 2007). Parasite body size was thus used as a possible predictor of the presence/absence of eggs, the number of eggs and the size of the eggs at this level.

\section{Statistical analysis}

Relative contribution of abiotic and biotic factors on life-history traits. Our sampling design produced either 3 (for the body size of the parasite) or 4 (for the presence/absence of eggs, the number of eggs and the size of the eggs) levels of nesting with respect to the response variable. Therefore, in order to consider the influence of key biotic and abiotic variables on life-history traits of $T$. polycolpus, and to account for the statistical error structure imposed by the nested data, we implemented hierarchical (or multilevel) generalized linear models based on maximum likelihood to estimate parameters (HGLMs McMahon and Diez, 2007).

The models developed here were very simple in their formulations and were fitted using the 'Ime4' package in R (R Development Core Team, 2002). For each model we included predictor variables as fixedfactors. All predictors were initially centred around zero (using the function 'scale()' in R) to standardize all predictors and to facilitate the interpretation of slope coefficient estimates. The only exception was 'fin identity' as it was treated as a categorical predictor. At the microhabitat level, we included the interaction term between number of parasites and fin identity as we hypothesized that the relationship between parasite number and parasite life-history traits could vary according to fin identity (for instance, pelvic fins are thinner than the caudal fin and could be easier to degrade). Random factors correspond to each of the 3 or 4 levels considered, with the factor of the lower level being nested within the immediate factor of the upper level (e.g. host microhabitat level nested within host level). In summary, a nested structure corresponding to the nested sample design was used for fitting the random part of the model and to account for the statistical error structure imposed by this design (see Pinheiro and Bates, 2002). A 3-level model assuming a Gaussian error-term distribution was built for testing the variables that best predict the parasite body size. A 4-level model assuming a Binomial error-term was built for the presence/absence of eggs. Four-level models assuming a Gaussian error-term were built for the number of eggs and the size of the eggs. Each model was fitted by maximizing the restricted loglikelihood (REML method). The 95\% confidence interval for the estimate of each slope coefficient was estimated using Markov chain Monte Carlo (MCMC) sampling methods (5000 iterations). An estimate was considered as significant when its $95 \%$ interval does not include zero. The significance of the categorical predictor was assessed using log-ratio tests.

Unconditional models were initially fitted to determine the basic variance partitioning of each of the response variables among the 4 levels of association (Diez and Pulliam, 2007). In this kind of model, only the random part of the full model is considered and is used to calculate interclass correlation coefficients. Note that in these unconditional models, the random part contained 4 levels (parasite scale, microhabitat scale, host scale, site scale) for each response variable.

Trade-off between egg number and egg volume. We performed HGLM to test (i) for a trade-off between egg number and egg size in T. polycolpus and (ii) if the strength of this trade-off varied according to the surrounding environment. Female body size is known to affect this trade off (Herreras et al. 2007). Hence in this analysis, we used the residuals of linear models between egg size and parasite body size and between egg number and parasite body size as corrected measures of egg size and egg number respectively. In this HGLM, egg number (residuals) was the dependent variable and we included sampling sites' identity, host body size and egg size (residuals) as fixed predictors. A negative relationship between egg number and egg size would indicate a trade-off between these traits. To test for a potential effect of the surrounding environment on the strength of this trade-off, we tested 2 interaction terms since the surrounding environment of the parasite has $2 \mathrm{com}-$ ponents: its host and the characteristics of the sampling location. A significant interaction between egg size and host body size would indicate that the relationship between egg number and egg size varied according to the body size of the host. If a large host body size provides more energy for parasites, the strength of the trade-off should be weaker on larger hosts. The second interaction concerned egg size and sample site identity; a significant interaction would indicate that the relationship between egg number 


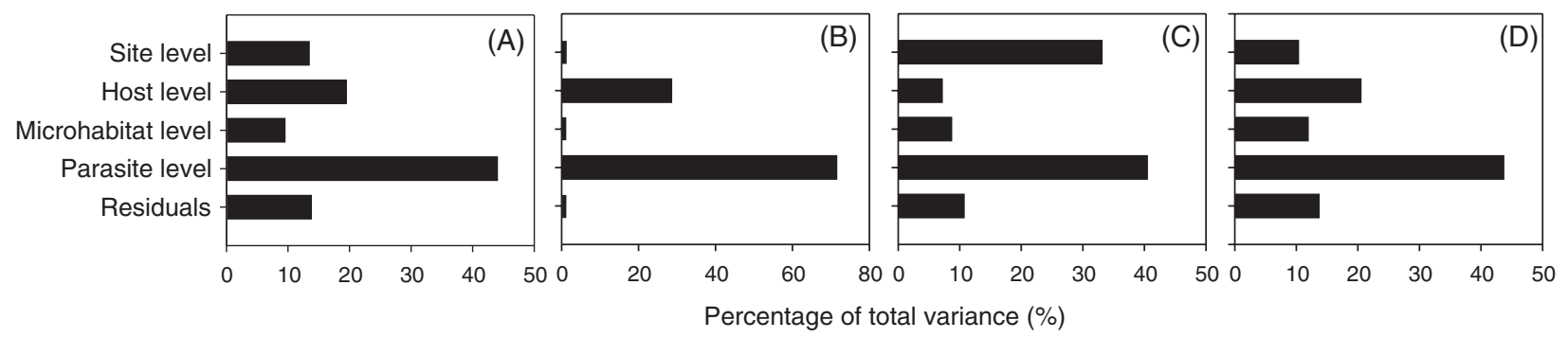

Fig. 1. Pattern of variance decomposition for 4 life-history traits of the ectoparasite Tracheliastes polycolpus, (A) parasite body size, (B) presence of eggs, (C) average size of the eggs per parasite and (D) number of eggs per parasite. The total observed variance for each trait was decomposed among 4 hierarchical levels of sampling, namely within site, within host, within microhabitat (i.e. the fins on which the parasite was sampled) and within parasite. For each trait, variance was decomposed using hierarchical linear models. 'Residuals' is the percentage of variance that was not explained by the 4 spatial levels under consideration.

and egg size varied according to the sampling location. Random effects were host identity nested within sampling sites.

\section{RESULTS}

\section{Variance partitioning}

Variance partitioning using unconditional models revealed that for the 4 life-history traits, more than $40 \%$ of the variation was distributed among parasites (Fig. 1). For the parasite body size, the number of eggs per parasite and the average size of eggs, greater than $20 \%$ of the variation was partitioned among hosts (Fig. 1A, C and D). Greater than $30 \%$ of the variation observed for the presence of eggs was distributed among sites (Fig. 1B).

\section{Relative contribution of abiotic and biotic factors on life-history traits}

The 4 traits exhibited different relationships with the biotic and abiotic variables in the full hierarchical models. For all traits except egg size (Fig. 2C) at least 1 of the variables selected had a significant effect on the response variable.

Both the parasite body size and the number of eggs showed similar patterns, with both traits being positively affected by the host body size and the number of parasites on each fin (Fig. 2A, D). The number of eggs was also significantly greater in larger parasites (Fig. 2D). The probability of carrying eggs was affected by several variables operating at multiple levels. First, the presence of eggs was affected by the size of the parasite, with the probability of carrying eggs being highest for parasites of intermediate body size (i.e. $\sim 3.5 \mathrm{~mm}$ ) (Fig. 2B, Fig. 3). This pattern was consistent for all sampled sites (Fig. 3). This indicates that the probability of carrying eggs increased until a maximum body size was reached, probably the size at which the parasite lays eggs. Second, the parasite number positively affected the probability of carrying eggs (Fig. 2B). Finally, the probability of carrying eggs increased as the host density and the water temperature within a site increased and decreased as the diatom index (i.e. the level of water quality) decreased (Fig. 2B).

There was no significant 'fin identity' effect for any of the 4 traits, and similarly no interaction term between fin identity and parasite number was significant (Table 2). This indicates that the relationships between parasite number, parasite body size, egg presence and egg number did not differ among fins.

\section{Trade-off between egg number and egg volume}

As above, we found a significant positive relationship between host body size and egg number (Table 3, slope coefficients not shown). Although no significant relationship between egg number and size was found, we highlighted a significant interaction between egg size and sampling site identity (Table 3 ).

Such an interaction indicates that the relationship between egg number and egg size varied according to sampling location. Particularly, a significant $(P<0.05)$ and negative relationship between egg number and egg size was found for 2 study sites (Fig. 4). We found no evidence for a significant relationship at the other sites. Similarly, we found no significant interaction term between egg size and host body size, indicating that the strength of the trade-off did not vary according to host body size. One sampling site was discarded from this analysis because no females sampled had eggs.

\section{DISCUSSION}

In this study, we demonstrated that life-history traits (body size and fecundity components) of a fish ectoparasite strikingly varied along a short environmental gradient. For most life-history traits, a large amount of this variation was observed among individual parasites. In addition, we found that each of the 4 life-history traits analysed was unique in its response to the determinants considered. Indeed, some traits demonstrated significant relationships 

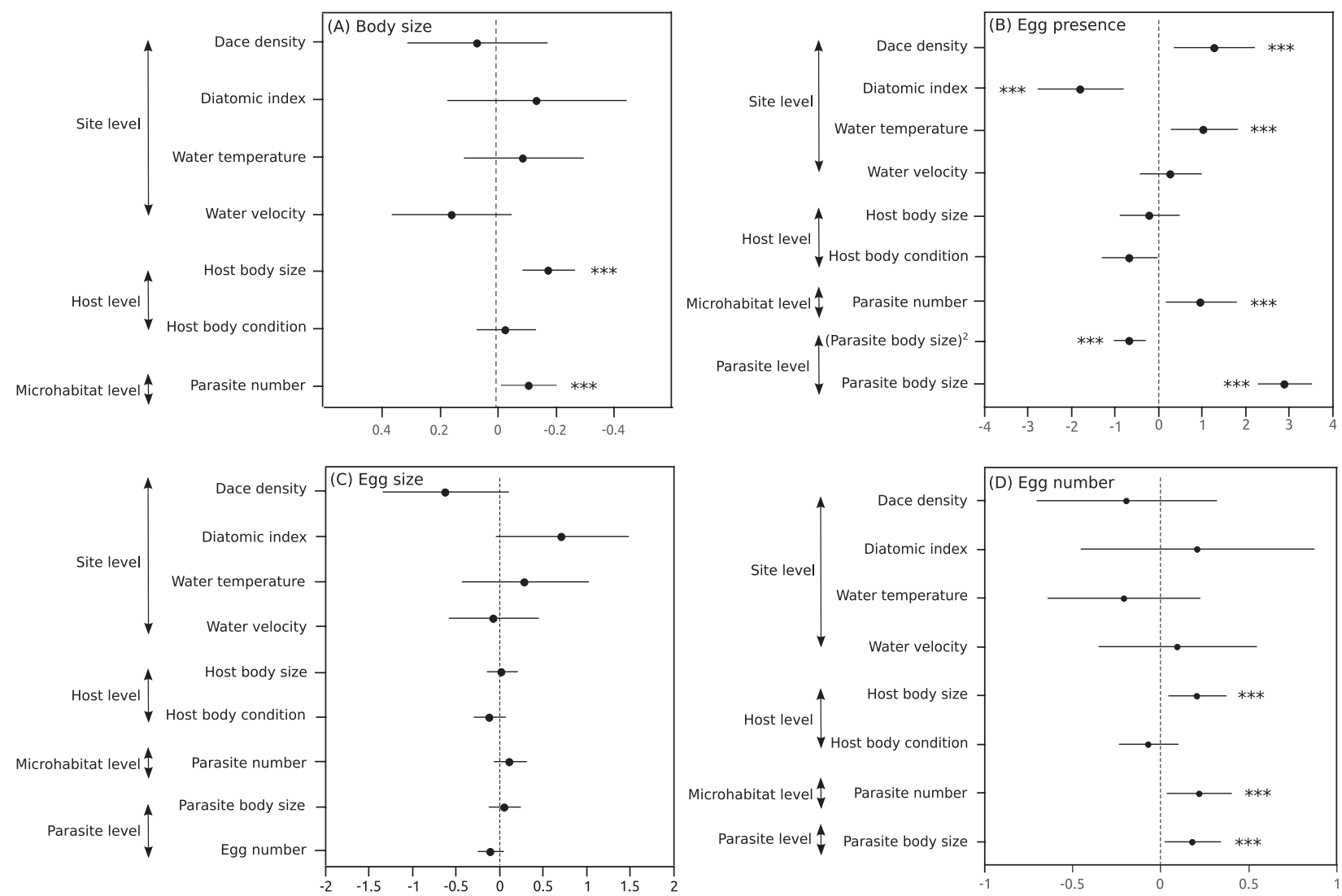

Fig. 2. Scale-explicit coefficient estimates. Solid lines represent $95 \%$ confidence interval effects of variables at 3-4 levels of the model (site level, host level, microhabitat level and parasite level). Intervals not overlapping the zero line are significantly different from zero. Dots represent point estimate of parameter value. Predictors of (A) parasite body size, (B) egg presence, (C) egg size, and (D) egg number. The asterisks $(* * *)$ indicate significant results $(P<0 \cdot 05)$.

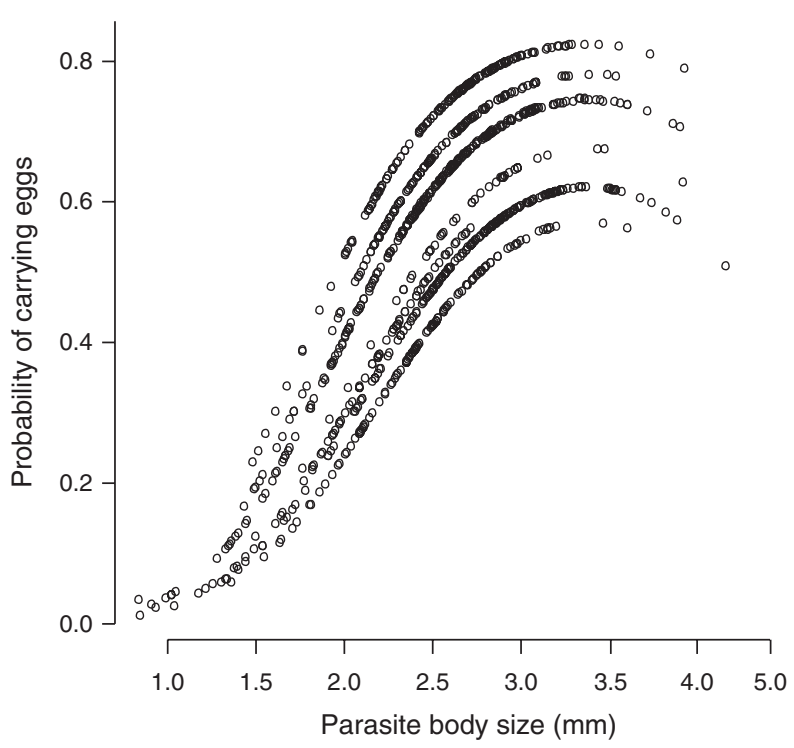

Fig. 3. Influence of the body size of the ectoparasite Tracheliastes polycolpus on the probability of carrying eggs. The probabilities of carrying eggs are those predicted from a linear-mixed model with binomial error term (see the main text). Parasites with intermediate body size had the higher probability of carrying eggs. The relationship is presented for each sampling site independently. with factors measured at the parasite level (e.g. the presence of eggs), while others showed significant relationships with factors measured at the microhabitat level (parasite body size, presence of eggs and eggs' number), the host level (parasite body size and eggs' number) and/or the environmental level (presence of eggs). Finally, we found evidence for a phenotypic trade-off between the number and the size of eggs, albeit the strength of this trade-off was site dependent.

We summarized in Fig. 5 the significant relationships between life-history traits and biotic and abiotic factors considered in this study. This figure highlights that parasite number measured at the microhabitat level (i.e. fins) is a significant predictor for 3 out of the 4 life-history traits we investigated. Particularly, we demonstrate significant positive relationships between fitness-related parameters and local parasite number, with parasites being larger, having a higher probability of laying eggs and producing a larger number of eggs when anchored to fins with high parasite numbers. This result was independent of the fin identity because parasite fitness did not differ among fins, which contrasts with the findings of Timi et al. (2010). Host body size is highly correlated to fin surface (Drucker and 
Table 2. Results of general linear mixed models used to evaluate the effects of various predictors on parasite body size, egg presence, egg size and egg number of the parasite Tracheliastes polycolpus

(Presented as statistical outputs for the categorical predictor (fin identity) included in the models, as well as for the interaction term between fin identity and the number of parasites per fin. Outputs for the other (continuous) predictors are presented in Fig. 2.)

\begin{tabular}{|c|c|c|c|}
\hline & D.F. & $\begin{array}{l}\mathrm{Log} \\
\text { ratio }\end{array}$ & $P$-value \\
\hline \multicolumn{4}{|l|}{ Parasite body size } \\
\hline Fin identity & 2,16 & $1 \cdot 787$ & $0 \cdot 775$ \\
\hline $\begin{array}{l}\text { Fin identity } * \text { Number of } \\
\text { parasites per fin }\end{array}$ & 2,12 & $6 \cdot 92$ & $0 \cdot 139$ \\
\hline \multicolumn{4}{|l|}{ Egg présence } \\
\hline Fin identity & 4,17 & $0 \cdot 65$ & 0.927 \\
\hline $\begin{array}{l}\text { Fin identity } * \text { Number of } \\
\text { parasites per fin }\end{array}$ & 4,21 & $1 \cdot 68$ & $0 \cdot 499$ \\
\hline \multicolumn{4}{|l|}{ Egg size } \\
\hline Fin identity & 2,15 & $1 \cdot 755$ & $0 \cdot 781$ \\
\hline $\begin{array}{l}\text { Fin identity } * \text { Number of } \\
\text { parasites per fin }\end{array}$ & 2,19 & $1 \cdot 856$ & $0 \cdot 762$ \\
\hline \multicolumn{4}{|l|}{ Egg number } \\
\hline Fin identity & 2,14 & $4 \cdot 095$ & $0 \cdot 393$ \\
\hline $\begin{array}{l}\text { Fin identity } * \text { Number of } \\
\text { parasites per fin }\end{array}$ & 2,18 & $1 \cdot 528$ & $0 \cdot 822$ \\
\hline
\end{tabular}

Lauder, 2002), so we can assume that the parasite number per fin is a good surrogate of parasite density in our analyses. Hence, although correlation is not causation, we can reasonably argue that higher local parasite numbers, irrespective of host body size and fin identity, favour individual parasite fitness. This result is in opposition to the general expectation that the number of conspecifics sharing a host constrains resource availability (i.e. the carrying capacity hypothesis; Hughes et al. 2004), and hence decreases individual fitness. For instance, parasites have the potential of reaching their maximum body size only when they do not share their host with conspecifics (Poulin, 1998). In addition, it has been shown that high within-host competition negatively affects per capita egg production of many helminth parasite species (Jones et al. 1989). Our study is one of the first to reveal a positive effect of conspecifics on individual fitness traits (but see Rossin et al. 2005 for a weak tendency with egg number). This positive density dependence (a kind of Allee effect) may result from within-host additive actions of parasites sharing a fin. Parasites may, for instance, act synergistically to produce tissue-damaging compounds (Whiteman et al. 2004), or suppress the immune system.

At the host level, we found that host body size was positively correlated with parasite body size and egg number. Several studies have demonstrated that the overall quality of host-related to its age, size, diet or immune status-affected the reproductive success,
Table 3. Results of a General linear model used to evaluate the effects of sampling site, host body size and the egg size on the egg number of the parasite Tracheliastes polycolpus

(The 2-term interactions were considered to test for the existence of a trade-off between number and size of eggs. Significant $P$-values $(P<0 \cdot 05)$ are in bold.)

\begin{tabular}{llrr}
\hline \hline & D.F. & F-value & $P$-value \\
\hline Sampling site & 6,45 & $2 \cdot 033$ & $0 \cdot 080$ \\
Host body size & 1,45 & $18 \cdot 620$ & $<\mathbf{0 . 0 0 1}$ \\
Egg size & 1,130 & $0 \cdot 207$ & 0.646 \\
Sampling site $*$ Egg size & 6,130 & 3.139 & $\mathbf{0 . 0 0 7}$ \\
Host body size $*$ Egg size & 1,130 & $0 \cdot 348$ & $0 \cdot 556$ \\
\hline \hline
\end{tabular}

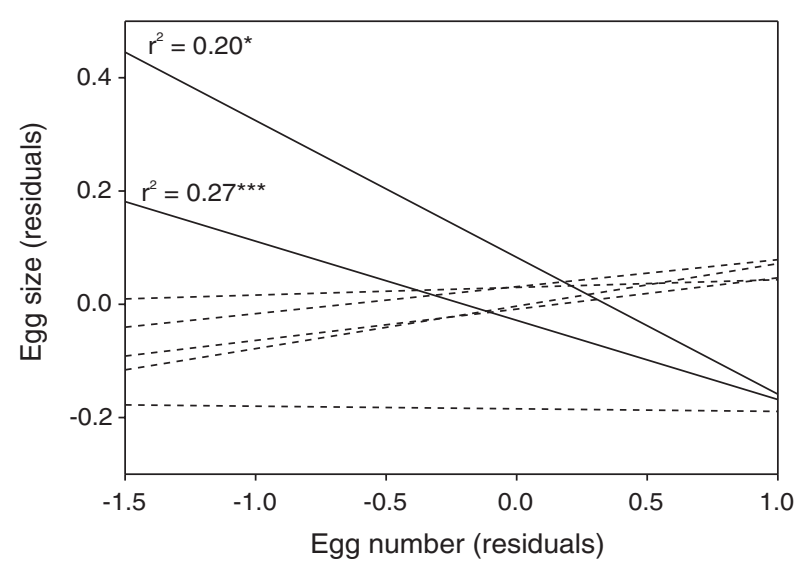

Fig. 4. Results of regression analysis between egg number (residuals) and egg size (residuals) of 7 populations of Tracheliastes polycolpus. Straight solid lines indicate significant trends (* $P<0 \cdot 05$;

*** $P<0 \cdot 001)$. Stippled lines indicate non-significant relationship.

and hence the fitness of parasites (Quinnell, 1988; Seppala et al.2008). Tsai et al. (2001) showed that the body size of the fish host Varicorhinus bacbatulus positively affected clutch size of the parasitic isopod Ichthyoxenus fushanensis. Similarly, a positive association between host body size and parasite body size has already been documented in other host-parasite systems (Jennings and Calow, 1975; Poulin, 1995b; Tsai et al. 2001) and has been proposed as a space and/or food constraint imposed by the host. In our case, we can speculate that large hosts directly provide higher nutritional inputs to parasites, or are weaker in mounting an efficient immune response against parasites (Seppala et al. 2008). However, although the use of standardized coefficient regression is supposed to assess the independent strength of each factor (Murray and Conner, 2009), one cannot totally rule out the possibility of an indirect effect of host body size. Indeed, larger and older hosts display higher T. polycolpus loads (Blanchet et al. 2009); we can hence speculate that because larger and older hosts have a higher parasite load, the number of parasites is higher at the microhabitat level, which 


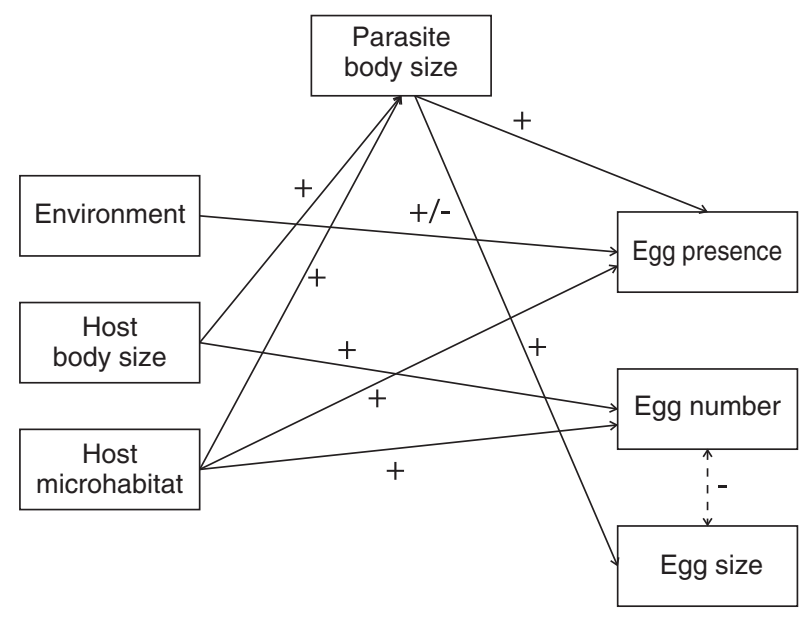

Fig. 5. Path diagram revealing the interactions between life-history traits of parasite Tracheliastes polycolpus (parasite body size and reproductive output variables) and host and environmental factors.

increases the individual fitness of parasites. In this context, the positive association between parasite number and fitness would be an indirect consequence of differences among host 'quality'. Additional studies that make use of causal modelling (Grace, 2006) should be performed to decipher between direct or indirect effects of bigger hosts on parasite fitness.

At the environmental level, we found that dace density, water quality and water temperature significantly affected the presence of eggs in T.polycolpus. No other life-history traits were affected by environmental level factors. Concerning the presence of eggs, there was a higher probability of finding a $T$. polycolpus with eggs in sites with a high density of dace, a low diatom index (i.e. site with a weaker than the mean water quality) and a high water temperature. The positive relationship between water temperature and egg presence might indicate a temporal asynchrony among sites, implying that parasites develop eggs earlier in the season in warmer sites. However, at this step, speculation about the process underlying these relationships between environmental characteristics and life-history straits is still complex and uncertain. These results need to be tested in the laboratory before drawing conclusions about mechanisms underlying these patterns. However, a very important result is that environmental variation did not seem to be the most important component of life-history trait variation in $T$. polycolpus. Indeed, as stated above, environment-level factors were significantly linked to a single trait while microhabitat level factors affected 3 out of the 4 life-history traits investigated here. In addition, unconditional models reveal that most of the variation in all life-history traits was observed at the parasite level. This latter finding suggests that the environment may have a limited effect on T. polycolpus life-history traits, and that unmeasured factors (e.g. hatching date, relatedness, genetic background ...) at the parasite level would be better candidate factors for future studies.

Finally, we report interesting and new patterns concerning the trade-off between egg size and egg number in parasites. Indeed, we found no general trade-off between egg size and egg number when all data from all sites were pooled. However, a closer look at this relationship highlights 2 significant trade-offs for 2 out of the 7 sampling sites. It is noteworthy that the 2 sampling sites showing a significant trade-off (Fuel and Serres) were geographically very close to each other $(<3 \mathrm{~km})$. Our result provides one of the few demonstrations that the shape and strength of a trade-off can vary within a parasite's population. Hosts are often viewed as unlimited food sources for parasites, which has been argued to override conflicts between energetically demanding traits such as egg size and the number of eggs (Rossin et al. 2005; Timi et al. 2005; Herreras et al. 2007). Accordingly, we found no evidence that the host body size affected the existence and strength of this trade-off. Another hypothesis suggests that, in nematodes, spatial constrictions imposed by uterine size may play an important role in determining the emergence of a trade-off between egg size and the number of eggs at the interspecific level (Herreras et al. 2007). This hypothesis is rather unlikely in our case since we are dealing with intraspecific variation, and because egg sacs are external in T. polycolpus. Therefore, our study provides a potentially new explanation for understanding intraspecific variability in the tradeoff between egg size and the number of eggs. Indeed, our result suggests that the strength (in fact the existence) of this trade-off strikingly depends upon the surrounding environment. It is noteworthy that, even if not demonstrated for $T$. polycolpus, some parasitic Copepods are able to produce repeated clutches in their lifetime (de Meeûs et al. 1993), which could mask the trade-off between egg number and size. Hence, if confirmed in the laboratory and after accounting for potential multiple clutches, our finding would indicate that, as for free-living organisms (Dobson and Murie, 1987; Stearns, 1992), the evolution of life-history trade-offs in parasites might depend upon environmental factors that could affect (either directly or indirectly) the acquisition of resources and/or the differential allocation of resources in life-history traits.

\section{Conclusion}

Although each trait had a unique response to biotic and abiotic factors, we found that variation in lifehistory traits was particularly related to unmeasured parasite-level factors and host-level factors rather than environmental-level factors. Reproductive strategies of parasites affect the opportunities for 
transmission and determine the spatial and temporal dynamic of pathogens (Wimberly et al. 2008). Thus, understanding the forces that shape the life-history traits of parasites is of interest for anyone interested in epidemiology, control strategies, and evolutionary medicine (Thomas et al. 2002). In such a context, our results highlight the importance of considering parasite life-history traits in a statistical framework that explicitly considers multiple biological levels (Vignon and Sasal, 2010). Changes in host conditions and parasite characteristics must, for instance, also be considered in order to predict parasite spread after environmental changes (Lafferty, 2009b).

This paper also showed that variation in the tradeoff between egg size and egg number exists in parasites, even within a single population. The existence of this trade-off varied between sites, which shows that the allocation of energy in parasites depends not only on intrinsic factors and host conditions. Hence, under particular conditions, the evolution of life-history traits in parasites might be constrained by competing resource allocations. This result shows that trade-offs can arise even if parasites are supposed to live in resource-rich habitats; other mechanisms than direct resource competition can indeed interfere with the allocation between egg size and egg number (Herreras et al. 2007).

Overall, this paper provides an example where a greater coupling of hierarchical study designs and appropriate analyses allow the determination of the ecological processes that drive the spatial variation of life-history traits of parasites and phenotypic trade-offs. This kind of correlative approach is a first step towards better designed and targeted laboratory experiments.

\section{ACKNOWLEDGMENTS}

We are indebted to Nicolas Soubiran, Fabien Leprieur, Muriel Gevrey, Yasmina Younes-Baraillé, Marc Dubois, Gaël Grenouillet, Roselyne Etienne, Alain Blanchet and Marie-Madeleine Furet who helped us in the field. The study was supported by the Adour-Garonne French Water Agency (Project no. 0601711).

\section{REFERENCES}

Anderson, R. M. (1993). Epidemiology. In Modern Parasitology (ed. Cox, F. E. G.), pp. 75-116. Blackwell, Oxford, UK.

Arneberg, P., Skorping, A., Grenfell, B. and Read, A. F. (1998). Host densities as determinants of abundance in parasite communities. Proceedings of the Royal Society of London, B 265, 1283-1289.

Barber, I. (2005). Parasites grow larger in faster growing fish hosts. International fournal for Parasitology 35, 137-143.

Blanchet, S., Méjean, L., Bourque, J.F., Lek, S., Thomas, F., Marcogliese, D. J., Dodson, J. J. and Loot, G. (2009). Why parasitized hosts look different? Resolving the "chicken-egg" dilemma. Oecologia 160, $37-47$.

Blanckenhorn, W. U. and Heyland, A. (2004). The quantitative genetics of two life history trade-offs in the yellow dung fly in abundant and limited food environments. Evolutionary Ecology 18, 385-402.
Bohlin, T., Hamrin, S., Heggberget, T. G., Rasmussen, G. and Saltveit, S. J. (1989). Electrofishing-theory and practice with special emphasis on salmonids. Hydrobiologia 173, 9-43.

Boxshall, G. (2005). Crustacean parasites In Marine Parasitology, (ed. Rohde, K.), pp. 147-149. Collingwood, Vic., Australia.

Byers, J.E., Blakeslee, A.M.H., Linder, E., Cooper, A.B. and Maguire, T. J. (2008). Controls of spatial variation in the prevalence of trematode parasites infecting a marine snail. Ecology 89, 439-451.

Carle, F. L. and Strub, M. R. (1978). A new method for estimating population size from removal data. Biometrics 34, 621-830.

Combes, C. (2001). The Ecology and Evolution of Intimate Interactions. Chicago University Press, Chicago, IL, USA.

Cox, E. (1991). What is the Basis for Using Diatoms as Monitors of River Quality? (ed. Whitton, B. A., Rott, E. and Friedrich, G.), pp. 33-40. Institut für Botanik, Universität Innsbruck, Austria.

Crompton, D.W. T. (1991). Nutritional interactions between hosts and parasites. In Parasite-host Associations: Coexistence or Conflict? (ed. Toft, C. A., Aeschlimann, A. A. and Bolis, L.), pp. 228-257. Oxford University Press, New York, USA.

Diez, J. M. and Pulliam, H. R. (2007). Hierarchical analysis of species distributions and abundance across environmental gradients. Ecology 88, 3144-3152.

de Meeûs, T., Raibaut, A. and Renaud, F. (1993). Comparative life history of two species of sea lice. In Pathogens of Wild and Farmed Fish (ed. Boxsiiat, L. and Defaye, D.), pp. 61-67. Ellis Horwood, New York, USA.

Dobson, F. S. and Murie, J. O. (1987). Interpretation of intraspecific life history patterns: evidence from Columbian ground squirrels. The American Naturalist 129, 382-397.

Drucker, E. G. and Lauder, G. V. (2002). Experimental hydrodynamics of fish locomotion: functional insights from wake visualization. Integrative and Comparative Biology 42, 243-257.

Eisen, R. J. and Schall, J. J. (2000). Life history of a malaria parasite (Plasmodium mexicanum): independent traits and basis for variation. Proceedings of the Royal Society of London, B 267, 793-799.

Fryer, G. (1982). The Parasitic Copepoda and Branchiura of British Freshwater Fishes. A Handbook and Key. Freshwater Biological Association Scientific Publication. The Ferry House, Ambleside, Cumbria.

Grace, J. B. (2006). Structural Equation Modelling and Natural Systems. Cambridge University Press, Cambridge, UK.

Grenfell, B. and Harwood, J. (1997). (Meta)population dynamics of infectious diseases. Trends in Ecology \& Evolution 12, 395-399.

Grenouillet, G., Brosse, S., Tudesque, L., Lek, S., Baraille, Y. and Loot, G. (2008). Concordance among stream assemblages and spatial autocorrelation along a fragmented gradient. Diversity and Distributions 14, 592-603.

Hakalahti, T., Hakkinen, H. and Valtonen, E. T. (2004). Ectoparasitic Argulus coregoni (Crustacea : Branchiura) hedge their bets-studies on egg hatching dynamics. Oikos 107, 295-302.

Hawlena, H., Abramsky, Z., Krasnov, B. R. and Saltz, D. (2007). Host defence versus intraspecific competition in the regulation of infrapopulations of the flea Xenopsylla conformis on its rodent host Meriones crassus. International Fournal for Parasitology 37, 919-925.

Herreras, M. V., Montero, F. E., Marcogliese, D. J., Raga, J. A. and Balbuena, J. A. (2007). Phenotypic tradeoffs between egg number and egg size in three parasitic anisakid nematodes. Oikos 116, 1737-1747.

Hughes, W. O. H., Petersen, K.S., Ugelvig, L. V., Pedersen, D., Thomsen, L., Poulsen, M. and Boomsma, J. J. (2004). Densitydependence and within-host competition in a semelparous parasite of leafcutting ants. Bmc Evolutionary Biology 4, 45.

Jennings, J. B. and Calow, P. (1975). The relationship between high fecundity and the evolution of endoparasitism. Oecologia 31, 109-115.

Jessup, C. M. and Bohannan, B. J. M. (2008). The shape of an ecological trade-off varies with environment. Ecology Letters 11, 947-959.

Jones, J. T., Breeze, P. and Kusel, J. R. (1989). Schistosome fecundity influence of host genotype and intensity of infection. International Yournal for Parasitology 19, 769-777.

Kabata, Z. (1986). Redescriptions of and comments on four little-known Lernaeopodidae (Crustacea: Copepoda). Canadian fournal Zoology 64, 1852-1859.

Kabata, Z. and Cousens, B. (1973). Life cycle of Salmincola californiensis (Dana, 1852) (Copepoda: Lernaeopodidae). Fournal of the Fisheries Research Board of Canada 30, 881-903.

Keitt, T.H. and Urban, D. L. (2005). Scale-specific inference using wavelets. Ecology 86, 2497-2504.

Krasnov, B., Khokhlova, I. and Shenbrot, G. (2002). The effect of host density on ectoparasite distribution: An example of a rodent parasitized by fleas. Ecology 83, 164-175. 
Krist, A. C., Jokela, J., Wiehn, J. and Lively, C. M. (2004). Effects of host condition on susceptibility to infection, parasite developmental rate, and parasite transmission in a snail-trematode interaction. Fournal of Evolutionary Biology 17, 33-40.

Lafferty, K. D. (2009a). The ecology of climate change and infectious diseases. Ecology 90, 888-900.

Lafferty, K.D. (2009b). Calling for an ecological approach to studying climate change and infectious diseases. Ecology 90, 932-933.

Lecointe, C., Coste, M. and Prygiel, J. (1993). Omnidia software for taxonomy, calculation of diatom indices and inventories management. Hydrobiologia 269/270, 509-513.

Loot, G., Poulet, N., Reyjol, Y., Blanchet, S. and Lek, S. (2004). The effects of the ectoparasite Tracheliastes polycolpus (Copepoda: Lernaeopodidae) on the fins of rostrum dace (Leuciscus leuciscus burdigalensis). Parasitology Research 94, 16-23.

McMahon, S. M. and Diez, J. M. (2007). Scales of association: hierarchical linear models and the measurement of ecological systems. Ecology Letters 10, 437-452.

Morand, S. (1996). Life-history traits in parasitic nematodes: A comparative approach for the search of invariants. Functional Ecology 10, 210-218. Murray, K. and Conner, M. M. (2009). Methods to quantify variable importance: implications for the analysis of noisy ecological data. Ecology 90 348-355.

Nash, R. D. M., Valencia, A.H. and Geffen, A. J. (2006). The origin of Fulton's condition factor-Setting the record straight. Fisheries 31 , 236-238.

Patrick, M. J. (1991). Distribution of enteric helminths in Glaucomys volan L (Sciuridae). A test for competition. Ecology 72, 755-758.

Pinheiro, J. C. and Bates, D. M. (2002). Mixed-Effects Models in S and $S$-Plus. SPRINGER, New York.

Poulin, R. (1995a). Evolution of parasite life history traits: myths and reality. Parasitology Today 11, 342-345.

Poulin, R. (1995b). Clutch size and egg size in free-living parasitic copepodes: a comparative analysis. Evolution 49, 325-336.

Poulin, R. (1998). Evolutionary Ecology of Parasites. Chapman \& Hall, London, UK.

Quinnell, R. J. (1988). Host age and the growth and fecundity of Hymenolepis diminuta in the rat. Fournal of Helminthology 62,158-162.

R Development Core Team (2005). R: A Language and Environment for Statistical Computing. R Foundation for Statistical Computing, Vienna, Austria.

Roff, D. A. (1992). The Evolution of Life Histories: Theory and Analysis. Chapman and Hall, New York, USA.
Rossin, M. A., Poulin, R., Timi, J. T. and Malizia, A. I. (2005). Causes of inter-individual variation in reproductive strategies of the parasitic nematode Graphidioides subterraneus. Parasitology Research 96, 335-339. Schluter, D., Price, T. D. and Rowe, L. (1991). Conflicting Selection Pressures and Life-History Trade-Offs. Proceedings of the Royal Society of London, B 246, 11-17.

Seppala, O., Liljeroos, K., Karvonen, A. and Jokela, J. (2008) Host condition as a constraint for parasite reproduction. Oikos 117, 749-753.

Smith, C. C. and Fretwell, S. D. (1974). The optimal balance between size and number of offspring. American Naturalist 108, 499-506.

Stearns, S. C. (1992). The Evolution of Life Histories. Oxford University Press, New York, USA.

Taylor, J. C., Prygiel, J., Vosloo, A., de la Rey, P. A. and van Rensburg, L. (2007). Can diatom-based pollution indices be used for biomonitoring in South Africa ? A case study of the Crocodile West and Marico water management area. Hydrobiologia 592, 455-464.

Thomas, F., Brown, S. P., Sukhdeo, M. and Renaud, F. (2002). Understanding parasite strategies: a state-dependent approach? Trends in Parasitology 18, 387-390.

Timi, J. T., Lanfranchi, A. L. and Poulin, R. (2005). Is there a trade-off between fecundity and egg volume in the parasitic copepod Lernanthropus cynoscicola? Parasitology Research 95, 1-4.

Timi, J. T., Lanfranchi, A. L. and Poulin, R. (2010). Consequences of microhabitat selection for reproductive success in the parasitic copepod Neobrachiella spinicephala (Lernaeopodidae). Parasitology 137 1687-1694.

Tsai, M. L., Li, J. J. and Dai, C. F. (2001). How host size may constrain the evolution of parasite body size and clutch size. The parasitic isopod Ichthyoxenus fushanensis and its host fish, Varicorhinus bacbatulus, as an example. Oikos 92, 13-19.

Vignon, M. and Sasal, P. (2010). Multiscale determinants of parasite abundance: A quantitative hierarchical approach for coral reef fishes. International Fournal for Parasitology 40, 443-451.

Whiteman, N. K., Santiago-Alarcon, D., Johnson, K.P. and Parker, P. G. (2004). Differences in straggling rates between two genera of dove lice (Insecta: Phthiraptera) reinforce population genetic and cophylogenetic patterns. International fournal for Parasitology 34 1113-1119.

Wimberly, M. C., Yabsley, M. J., Baer, A. D., Dugan, V. G. and Davidson, W. R. (2008). Spatial heterogeneity of climate and land-cover constraints on distributions of tick-borne pathogens. Global Ecology and Biogeography 17, 189-202. 